\title{
Interventional Cohort Study for evaluation of Computer Vision Syndrome among Computer Workers
}

\author{
Gupta $\mathbf{R}^{1}$, Gour $\mathbf{D}^{2}$, Meena $\mathbf{M}^{3}$ \\ ${ }^{1}$ Dr Rachna Gupta, Associate Professor in Ophthalmology, ${ }^{2}$ Dr D Gour, Associate Professor, Community Medicine, ${ }^{3}$ Dr \\ Mamta Meena, Demonstrator, Community Medicine. All are affiliated with Gandhi Medical College, Bhopal, India
}

Corresponding Author: Dr Rachna Gupta, Email: drrachnagupta2k@gmail.com

\section{Introduction:}

The American Ophthalmological Association defines CVS as that "complex of eye vision problems related to near work which are experienced during or related to computer use." The most prevalent ophthalmologic symptoms associated are headache, dryness of eyes, watering, eye strain, redness, grittiness, blurring of vision which are often overlooked but are preventable at the same time. According to American Journal of Ophthalmology, $70-75 \%$ of computer workers have eye problems which are the most frequently related health problems. We have conducted this study to assess the asthenopic symptoms occurring in computer workers. Method: This study was done on 330 people working at Bhopal and symptoms related to CVS were studied during the pre and post interventional period of 3 months. Result: The intervention was able to decrease asthenopic complaints of computer workers to $46.5 \%$. Conclusion: There was a significant decrease in the asthenopic symptoms following intervention but limited results were achieved due to inadequate infrastructure in work place, non-compliance of the subjects, limited time of intervention.

Keywords: Computer vision syndrome, Asthenopia, CVS, Eye strain

\section{Introduction}

Computers are one of the most fascinating inventions of the 20th century. However, computer users come up with new challenges at their workplace and school system. By working for too long using a computer monitor systemic and ocular symptoms can develop.

According to the National Institute of Occupational Safety and Health, computer vision syndrome affects some $90 \%$ of the people who work on computers for three hours or more a day. ${ }^{1}$ Prevalence of visual symptoms increased significantly in individuals who spent more than 4 hours working in front of video display terminals (VDTs). ${ }^{2}$ Out of the reported complaints eyestrain was the most common complaint, and the occurrence was much more for workers who used VDTs for at least 7 hours per day than seen in those who used display for short durations.

Amongst the complaints, eyestrain was most prevalent, followed by burning or irritated eyes, blurred vision, watering and red eyes. Sheedy and co workers studied that 1 out of 6 patients requiring eye examinations have a computer-related eye problem. ${ }^{3}$ Other study showed that $22 \%$ of computer workers have musculoskeletal problems such as neck problems, back problems, shoulder

Manuscript received: $14^{\text {th }}$ Aug 2013

Reviewed: $29^{\text {th }}$ Sep 2013

Author Corrected: $15^{\text {th }}$ Nov 2013

Accepted for Publication: $29^{\text {th }}$ Dec 2013 problems, and/or carpal tunnel syndrome. ${ }^{4}$ Eyestrain (sore or fatigued eyes) $(97.8 \%)$, Headache $(82.1 \%)$, Slowness in changing focusing distance (56\%), Eye irritation (burning, dryness, redness) (66\%), Neck, back \& shoulder pain $(55 \%)$ are also common symptoms. ${ }^{5}$ The prevalence of ocular symptoms seen among computer users ranges from $25-93 \%$ as reported by various investigators. ${ }^{6} 90 \%$ of school age children have computer access at home or in school and 98 million children in globally use a computer at home or in school for at least 4 hours per day.

Decreasing the amount of time spent in front of the computer will have a significant impact on symptoms associated with computer vision syndrome. It is suggested to follow the 20/20/20 rule, in which the computer user after working on a computer for 20 minutes, must look away at $20 \mathrm{ft}$ for at least 20 seconds ${ }^{7,8}$ This can significantly improve the work efficiency and prevent ocular symptoms. It is also very important to limit computer use with children as they have a lower degree of self awareness and often do not notice discomfort or other symptoms associated with computer vision syndrome.

The National Institute of Occupational Safety and Health (NIOSH) suggested that computer users should have an eye exam before working on a computer and once a year thereafter. Individuals should be sure to tell their 
optometrist how often and where they use a computer as well as the distance they normally sit from their computer. $^{9}$

The angle of inclination and position of monitor with respect to eye has influence on the visual discomfort. In a study by Rechichi, and Scullica (1990), it was shown that visual discomfort has a high correlation with height and inclination of computer monitor ${ }^{10}$. Therefore the use of an ergonomic position of the computer monitor and chair is highly recommended. Smaller angle of gaze leads to more CVS symptoms than large angle (14 degrees or more).

When we are using a computer the lighting should be half that of normal room illumination. This can be done with dimmer switches, closing blinds or shades, use of 3 way bulbs, or use of low intensity bulbs. Glare and reflections on computer screens can also cause eye strain. Glare is an issue with all monitors. CRT monitors causes more glare and potential strain issues due to screen dynamics and the screen constantly being "redrawn". ${ }^{11}$ The best technique to minimize glare is to use an anti-glare cover over the screen and use of flat screens as and when possible. ${ }^{12}$

It is advisable to take frequent breaks to reduce your risk of symptoms due to computer vision syndrome as well as for neck, back, and shoulder pain. One should make sure to stand up and move as well as look away from the computer and take frequent work break (at least once per hour) in order to prevent the eye strain associated by prolong eye work.$^{13}$

To maximize comfort when working on computer, one should talk to optometrist about a customized prescription made especially for computer working distance. This study was conducted to assess the asthenopic symptoms occurring in computer workers \& to reduce these symptoms after educational intervention.

\section{Material and Method}

Study design - cohort interventional study

Inclusion criteria -Persons not suffering from any ocular morbidity using computer for more than six hours

Exclusion criteria - persons suffering from any ocular morbidity

Ethical consideration - verbal consent was taken

\begin{tabular}{|c|c|}
\hline Study area & Persons \\
\hline Paryawas Bhawan & 45 \\
\hline EMRI, Id-Gah Hills & 55 \\
\hline Sure-Vin, Arera colony & 120 \\
\hline Sure -Vin, Kolar road & 110 \\
\hline Total study sample & $\mathbf{3 3 0}$ \\
\hline
\end{tabular}

\section{Procedure}

Survey and screening with special emphasis on duration of computer use, about workplace, water intake, work station and break time. Complete ocular examination was done specially blink rate, refractive error, schirmer's test.

Educational intervention (Training workshop \& Sensitization) includes:

1. Eye exercise

2. Ideal workstation setup

3. Eye health education

4. Distribution of pamphlets \& tear substitutes

5. Referral of suspected cases for further evaluation.

6. Post interventional survey

Instructions were given to all the people in the study group and were described collectively. Pamphlets were distributed about the points to be taken care of.

\section{Observation and results}

According to the pre interventional data asthenopia was found in about $83.60 \%$ of people. Musculoskeletal complaints were found in $36.2 \%$ people.

Table No 1: Asthenopic symptoms

\begin{tabular}{|c|c|}
\hline Symptoms & \% of people affected \\
\hline Slowness of focussing distance & 56 \\
\hline Dry eye & 66 \\
\hline Headache & 82.10 \\
\hline Eye strain & 83.60 \\
\hline
\end{tabular}

Majority of patient in our study were complaining of eye strain $(83.60 \%)$, followed by headache $(82.10 \%)$, then dry eye $(66 \%)$, and $56 \%$ cases observed slowness of focussing distance. 
Table No 2: Relation between duration of computer use and asthenopia

\begin{tabular}{|c|c|c|c|}
\hline $\begin{array}{c}\text { Duration of computer } \\
\text { use }\end{array}$ & Asthenopia present (\%) & Asthenopia absent (\%) & Total \\
\hline$<6$ months & $28(63.6)$ & $16(36.4)$ & 84 \\
\hline $6-12$ months & $66(75)$ & $22(25)$ & 61 \\
\hline $1-3$ yrs & $54(88.5)$ & $7(11.5)$ & 37 \\
\hline$>3$ yrs & $78(89.6)$ & $9(10.4)$ & $54(16.4)$ \\
\hline Total & $276(83.6)$ & & 330 \\
\hline
\end{tabular}

On evaluating patients with reference to duration of development of symptoms, we revealed that as the duration of computer use increases symptoms steadily. $89.6 \%$ patients develop ashtenopia after 3 years of computer usage.

Table No 3: Relation between contrast and brightness with asthenopia

\begin{tabular}{|c|c|c|}
\hline Adjust contrast and brightness & Ashenopia present & Asthenopia absent \\
\hline Not adjusted & 191 & 15 \\
\hline Adjusted & 85 & 39 \\
\hline Total & 276 & 54 \\
\hline
\end{tabular}

In the present study, ashtenopia was present in more number of of cases $92.7 \%$ (191) who did not adjust contrast and brightness as compared to patients who adjust brightness of computer screen $68.5 \%(85)$. Relative risk of developing asthenopic symptoms was 1.35 , and this is significant $(p=0.001)$

Table No 4: Relation between posture and screen level during computer use and asthenopia

\begin{tabular}{|c|c|c|}
\hline Screen level \& posture & Asthenopia present & Asthenopia absent \\
\hline Incorrect way & 183 & 16 \\
\hline Correct way & 93 & 38 \\
\hline Total & 276 & 54 \\
\hline
\end{tabular}

$\mathrm{RR}=1.24, \mathrm{p}<0.001$

In the present study asthenopia was present in majority of cases $91.5 \%(183)$, who did not use correct posture and screen level during computer use as compared who use correct posture and screen level during computer use $70.9 \%(93)$. The relative risk comes out to be 1.24 and this is highly significant $(p=0.001)$. Asthenopia is associated with incorrect eye level from screen centre (at or above). Distance from screen was also associated with asthenopia (<24 inch) as $89.2 \%$

Table no.5 Interventional results

\begin{tabular}{|c|c|c|}
\hline & Pre interventional (\%) & Post interventional (\%) \\
\hline Headache & 41.40 & 25.50 \\
\hline Dryness & 14.07 & 9.80 \\
\hline Watery eyes & 22.20 & 11.02 \\
\hline Eye strain & 32.50 & 12.99 \\
\hline Redness & 9.60 & 6.29 \\
\hline Gritiness & 14.07 & 10.60 \\
\hline Blurring of vision & 8 & 6.60 \\
\hline
\end{tabular}

In symptomatic patients, intervention in the form of eye health education, eye exercises \& work station management was done and post interventional results were encouraging. Majority of patients of headache (41.40\%) were relived (25.50\%), followed by eye strain from $32.5 \%$ to $12.99 \%$. Other symptoms watering and dryness of eye has also improved 


\section{Discussion}

There are very few interventional studies available regarding computer vision syndrome so comparison of our study with previous study regarding interventional results was a bit difficult.

As per a cross sectional study done on 150 subjects by Smita Agarwal et al in year 2012-13 there was significant association between headache and working distance and posture. ${ }^{1}$ In our study asthenopic symptoms were found in $70.9 \%$ of participants who adjusted posture as compared to $91.9 \%$ in those who did not adjust their posture while using computer $(\mathrm{RR}=1.24, \mathrm{p}<0.001)$.

The incidence of CVS is as high as $50-90 \%$ among the employees whose occupation involves computer use. It is estimated that approximately 45 million workers directly use computers, staring into VDTs for hours continuously. Also, a number of investigators have indicated that visual symptoms occur in $75-90 \%$ of VDT workers ${ }^{2}$. Our study is comparable with these studies. We observed that preinterventional asthenopia (83.6 \%) \& musculoskeletal complains were decreased after intervention. High prevalence of asthenopic complaints $(46.3 \%)$ in the computer users was also reported in a similar study done by other investigeters. ${ }^{15,16}$

In the study done by Smita et al, association of eye stain was found in computer users who did not adjust brightness of monitor. ${ }^{14} \mathrm{We}$ also found similar association between these factors.

Studies by Bergqvist UO et al, have reported increased odds ratios for certain eye discomfort symptoms when the computer operators kept the terminal at about the eye level rather than below the eye level ${ }^{18}$. Studies done by Jaschinski W et al, have found that high screens result in greater eyestrain than the low screens. ${ }^{17,19}$ Our study reveals significant relation of screen to eye level and asthenopic symptoms( $\mathrm{RR}=1.24, \mathrm{p}<0.001)$. Hence, computer users are invariably exposed to the risk of developing CVS, leading to marked deterioration in performance owing to the severity and persistence of disorders.

In our study we also observed that, as the duration of computer use increases. Asthenopic symptoms and other symptoms can be reduced by following steps. ${ }^{20}$

- $\quad$ Blink more often (12-18/minute)

- Take breaks frequently (20-20-20 rule) after every 20 minutes look at distant object at least 20 feet away for 20 seconds.

- Modify work place.

- Exercise \& stretch eyes.
- Monitor display quality-choose a setting in which refresh rate and resolution both are high no.

- Adjust the brightness of computer screen.

- Minimum glare: use anti glare screen to avoid eye strain if possible, paint white background with a darker, colour with a matte finish.

- Use proper lighting: avoid excessive or under lighting.

- Exercise even when sitting- stand up, move about or exercise arms, leg, back, neck, and shoulders frequently

- Plenty of water intake and tear substitute as and when required.

After adopting above steps, pre and post intervention results in symptomatic patients were encouraging.

\section{Conclusion}

The intervention was able to decrease asthenopic complints of computer workers to $46.5 \%$. Limitation of study includes non-compliance of the subjects, limited time of intervention to have sufficient outcome. CVS may take an epidemic form in near future. It is also imposing economic burden over financial infrastructure pertaining to decrease in working efficiency at workplace. Early evaluation, diagnosis, intervention and education may prevent the symptoms associated with CVS. Appropriate diagnosis and treatment of existing vision problems and control or elimination of environmental factors can effectively reduce the symptoms associated with computer use.

Funding: Nil

Conflict of interest: Nil

Permission from IRB: Yes

\section{References}

1. National Institute for Occupational Safety and Health (US) NIOSH Publications by Category.

2. Rossignol AM, Morse EP, Summers VM, Pagnotto LD. Visual display terminal use and reported health symptoms among Massachusetts clerical workers. J Occup Med 1987;29: 112-8

3. Sheddy JE, Shaw-McMinn PG (2003) Diagnosing and Treating Computer related Vision Problems, Ellsevier Health Sciences

4. Hales TR, Sauter SL, Peterson MR, Fine LJ, PutzAnderson V, Schleifer LR, Ochs TT, Bernard BP (1994) Ergonomics, 37(10), 1603-1621 
5. Blehm C, Vishnu S, Khattak A, Mitra S, Yee RW(2005) Survey of Ophthalmology, 50(3), 253-262.

6. Dr Sujatha Mohan, Computer vision syndrome, ejo, e journal of ophthalmology, 2011

7. Dinesh J Bhanderi, Sushilkumar Choudhary, Vikas G Doshi, A community based study of asthenopia in computer operators, IJO, 2008, vol 56, issue 1, pg 51-55

8. J.Tribleya et al, tips for computer vision syndrome relief and prevention, IE 2011, vol 39, Issue 1

9. Cole BL, Do visual Display units cause visual problems? - a bedside story about the process of public health decision-making. Clinical and Experimental Optometry: Journal of the Australian Optometrical Association 86(4) (2003), 205-220.

10. Rechichi and L. Scullica, Asthenopia and monitor characteristics, Istituto di Oftalmologia 13(8-9) (1990), 456-460.

11. T.W. Raasch et al, Office Ergonomics Handbook. Fifth Editon.(2008). Ocupational Health Clinics For Ontario Workers.

12. Garcia KD,Wierwille WW. Visual Performance at Video Display Terminals-Effects of Screen Color and Illuminant Type, Optometry And Vision Science 68(12)(1991),924-929.
13. Anshel J. Visual Ergonomics Handbook. In: Anshel J, editor. New York: Taylor and Francis; 2005

14. Agarwal S, Goel D, A Evaluation of the Factors which Contribute to the Ocular Complaints in Computer Users. Journal of clinical \& diagnostic research 2013, February 7(2): 331-335

15. Bhanderi DJ, Choudhary S, Doshi VG. A communitybased study of asthenopia in computer operators. Indian $\mathrm{J}$ Ophthalmol.2008; 56:51-55.

16. Mocci F, Serra A, Corrias GA. Psychological factors and visual fatigue in working with video display terminals. Occup Environ Med. 2001; 58:267-71.

17. Sanchez-Roman FR, Perez-Lucio C, Juarez-Ruiz C, Velez-Zamora NM, Jimenez-Villarruel M. Risk factors for asthenopia among computer terminal operators. Salud Publica Mex.1996; 38:189-96.

18. Bergqvist UO, Knave BG. Eye discomfort and work with visual display terminals. Scand J Work Environ Health. 1994; 20:27-33

19. Jaschinski W, Heuer H, Kylian H. Preferred position of visual displays relative to the eyes: A field study of visual strain and individual differences.Ergonomics.1998; 41:1034-49.

20. Kathy S. Tips for managing computer vision syndrome. AAOHN J 2005;53:12

\section{How to cite this article?}

Gupta R, Gour D, Meena M. Interventional Cohort Study for evaluation of Computer Vision Syndrome among Computer Workers. Int J Med Res Rev 2014;2(1):40-44, 10.17511/ijmrr.2014.i01.08 